\title{
ON VARIATION IN THE VENATION OF AN ARCTIAN WITH NOTES ON OTHER ALLIED GENERA.
}

BY HARRISON G. DYAR, BOSTON, MASS.

In examining the venation of Pyrrharctia isabella, I found a considerable range of variation. Seventeen specimens were examined and they varied in the following manner. In thirteen of them, vein ro of primaries arose from the stalk which bears veins $7-9$, at a variable distance from its origin (see pl. 19, fig. $3 a$ and $g$ ). This is to be considered the normal venation. In one specimen vein ro arose from the subcostal vein on the discal cell (fig. $3 f$ ), and in two others it arose from a stalk with vein II. In one of these latter, the stalk arose from the subcostal vein (fig. $3 c$ ) and in the other from the stalk which bears veins 7-9 (fig $3 b$ ). The latter specimen was further abnormal in lacking veins 4 and 5 of the primary of one side. Another variation is shown in fig. $3 a$ and $b$, in which either veins 7 and 8 or 8 and 9 are on a common stalk, that is to say in one case vein 9 is given off before 7 , and in the other, 7 before 9. A slight variation in the secondaries is shown in fig. $3 d$ and $e$, where veins 3 and 4 are either fused or well separated at origin.

There is here a sufficient range of variation among the subcostal venules to found four genera upon. Moreover, it is probable that other genera may vary as much, so that it would be well to consider this possibility in using such tables of genera as that by Prof. Smith in Can. ent., xxii, 233, where the origin of vein IO is used as an important character. While speaking of this table, I will mention that the genera Eupseudosoma, Nelphe and Ectypia are wrongly placed. The former lacks veins 5 and 8 of secondaries; the second also lacks vein 8 of secondaries and has veins 7-ro of primaries on a stalk; the third genus has an accessory cell, and should have been placed with Nemeophila. Prof. Smith states that two of these genera are placed by him partly by guess, as indeed seems evident.

Genus Spilosoma Steph. This genus differs from the new genera Neoarctia and Elpis recently established by Mr. Neumoegen and myself, in the position of the ocelli. In Spilosoma they are situated close on the margin of the eyes; in the new genera they are separated from the margin by a considerable space.

$S$. vestalis Pack. In specimens from Oregon the apex of the fore wings is more pointed and the outer margin more oblique than in those from California. The. black spots, too, seem less strongly marked, and I took several specimens at Portland in which the abdomen was quite immaculate. 


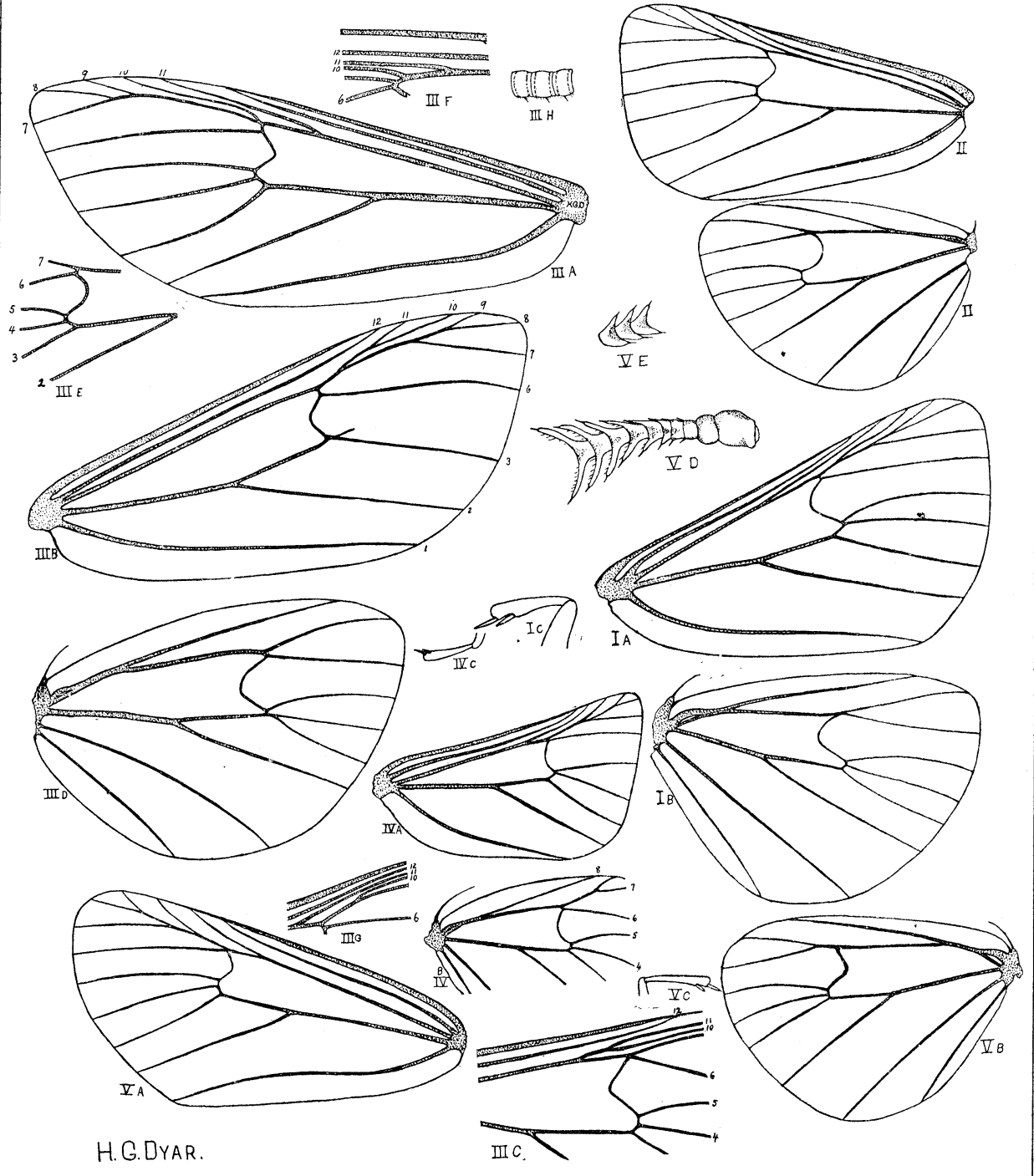


For this form, the varietal name amelaina would seem not inappropriate. They closely resemble $S$. latipennis in general coloration.

Genus Elpis Dyar. I have to correct a statement in my description of this genus (Ent. news, iv, 36). The median spurs of the hind tibiae are not absent as the wording implies, but are situated close to the posterior pair (pl. I9, fig $4 c$ ). The genus differs from Neoarctia in the shape of the front of the head, which is narrowed above and below, while in Neoarctia it is broad and square. Fig. $4 b$ shows vein 7 of secondaries furcate, as it was in one specimen. I am now of the opinion that Antarctia vagans Boisd. would be better placed in Elpis than in Spilosoma, since it has the ocelli distant from the eyes and the front narrowed above and below, though the vestiture and coloration are more like Spilosoma. I am greatly indebted to Mr. Thomas E. Bean of Laggan, Alberta for several specimens of Neoarctia beanii, from which the drawings on the plate were made (fig. $5 a-e$ ).

\section{Explanation of Plate i9.}

Fig. I $a$. Spilosoma virginica; venation of primary.

r $b$. Same; venation of secondary.

Ic. Same; hind tibia, showing spurs.

2. Phragmatobia rubricosa; venation.

3a. Pyrrharctia isabella; venation of primary.

$3 b$. Same; abnormal venation.

3c. Same; abnormal venation (partial).

$3^{d}$. Same; venation of secondary.

$3^{e}$. Same; venation of secondary (partial)

$3 f$. Same; origin of subcostal venules (abnormal).

$3 g$. Same; origin of subcostal venules (normal).

$3 h$. Same; three joints of $\delta$ antenna.

$4^{a}$ Elpis rubra; venation of primary.

$4 b$. Same; venation of secondary, showing variation.

4c. Same; hind tibia, showing spurs.

5a. Neoarctia beanii; venation of primary.

$5 b$. Same; venation of secondary.

$5 c$. Same; hind tibia, showing spurs.

$5 d$. Same; base of $\delta$ antenna.

$5 e$. Same; three joints of $q$ antenna.
Local Notes. - The Peabody academy of science of Salem has recently transferred to the entomological department of the Museum of comparative zoology of Cambridge a number of types of insects of various orders described by Dr. Packard; the types were in the exhibition cases at Salem and were overlooked when the greater part of the entomological collections of the Academy were deposited in Cambridge.

In Psyche v. 6, p. 316 it is noted that the volume on the animals and plants of Maine prepared by the late Dr. John W. Randall was unpublished. Recently we learned that the manuscript was placed in the hands of the Maine geological survey for publication and was subsequently lost. Dr. Randall's collection of insects was entirely destroyed many years ago. It may not be uninteresting to state that the Boston society of natural history received from Dr. Randall's estate the sum of $\$ 5000,-$ the income of which, in accordance with the wishes of Miss Randall, will be devoted to the library.

The gypsy moth has been found in Franklin Park, West Roxbury, outside the limits of the hitherto infected district as mapped two years ago. 

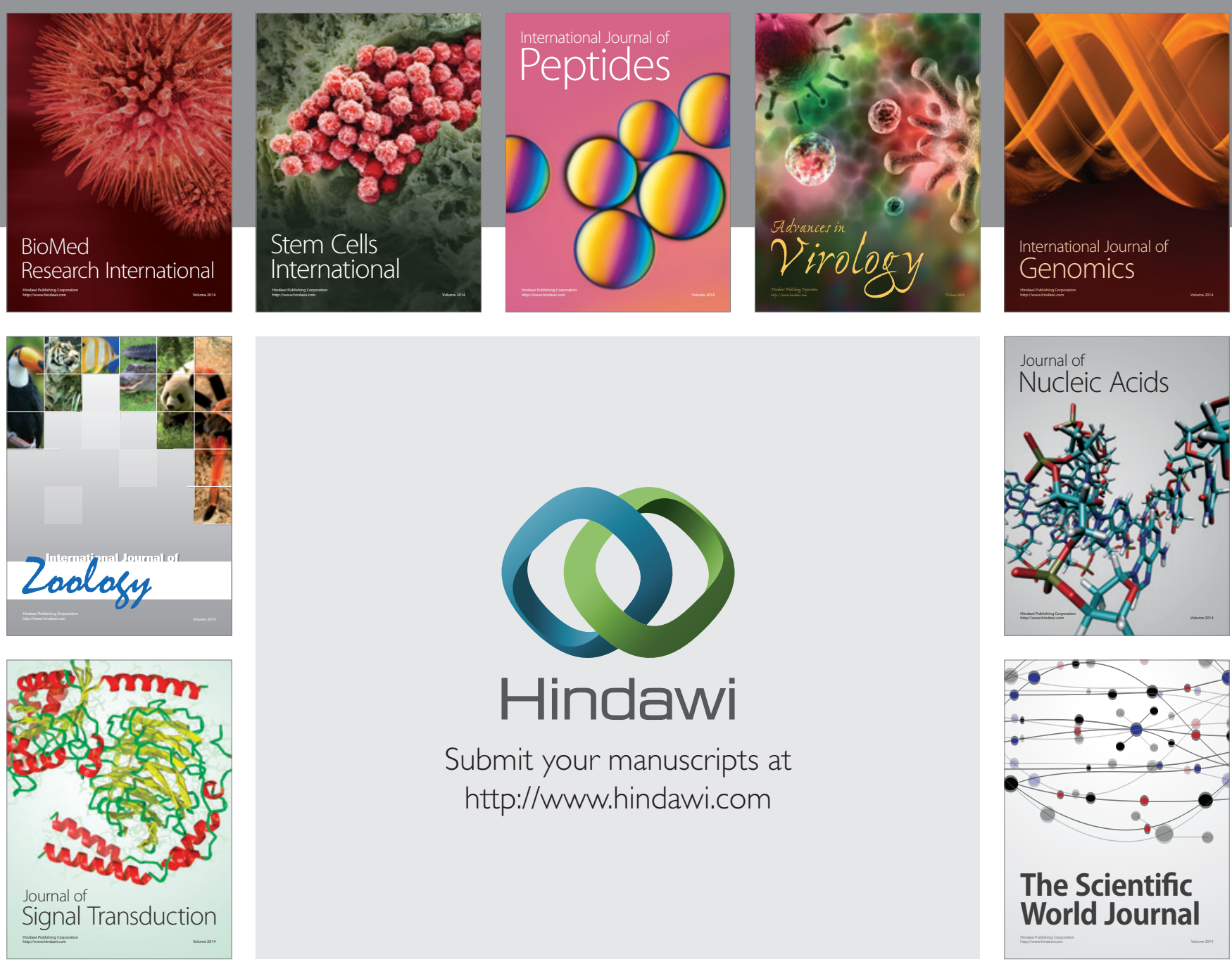

Submit your manuscripts at

http://www.hindawi.com
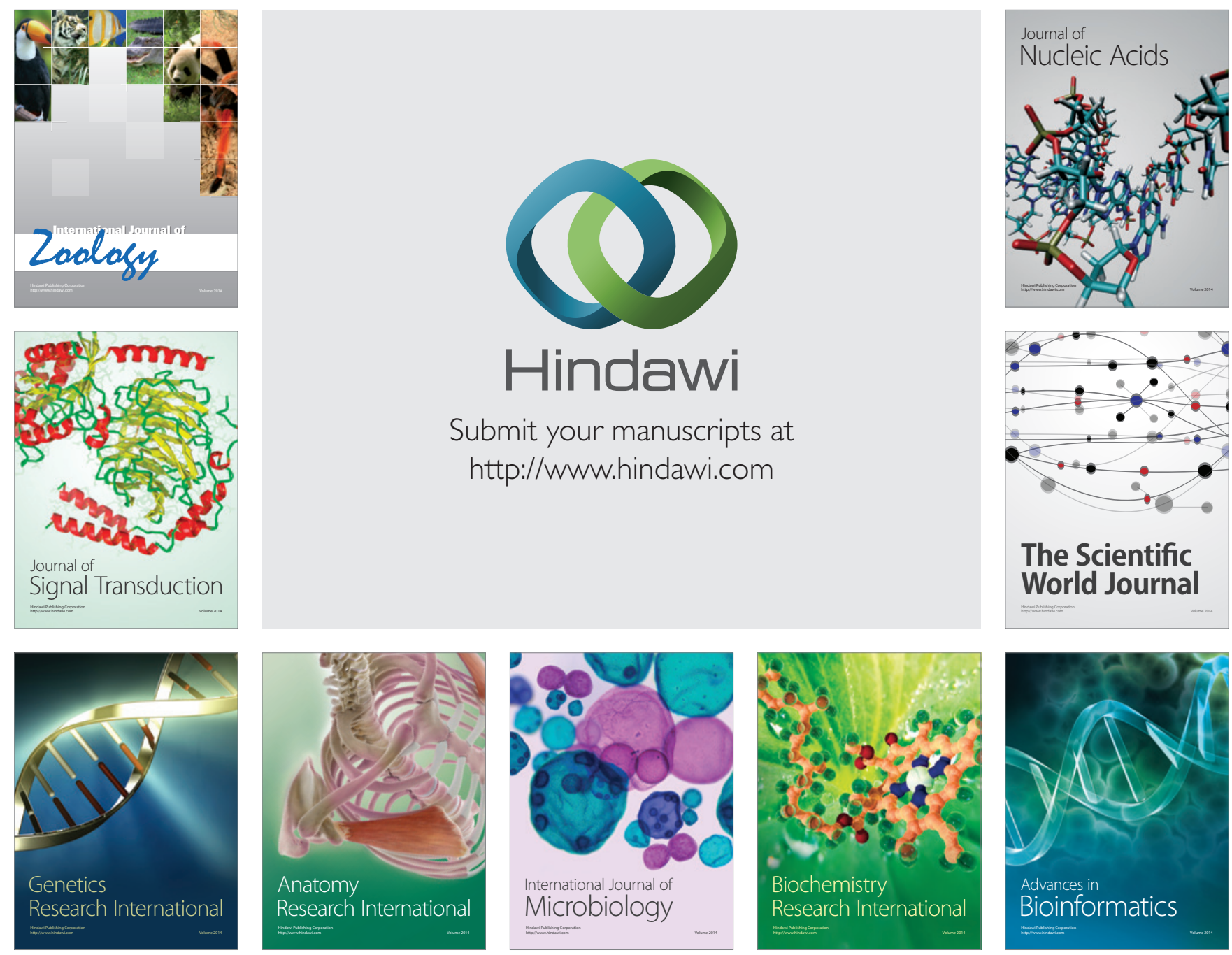

The Scientific World Journal
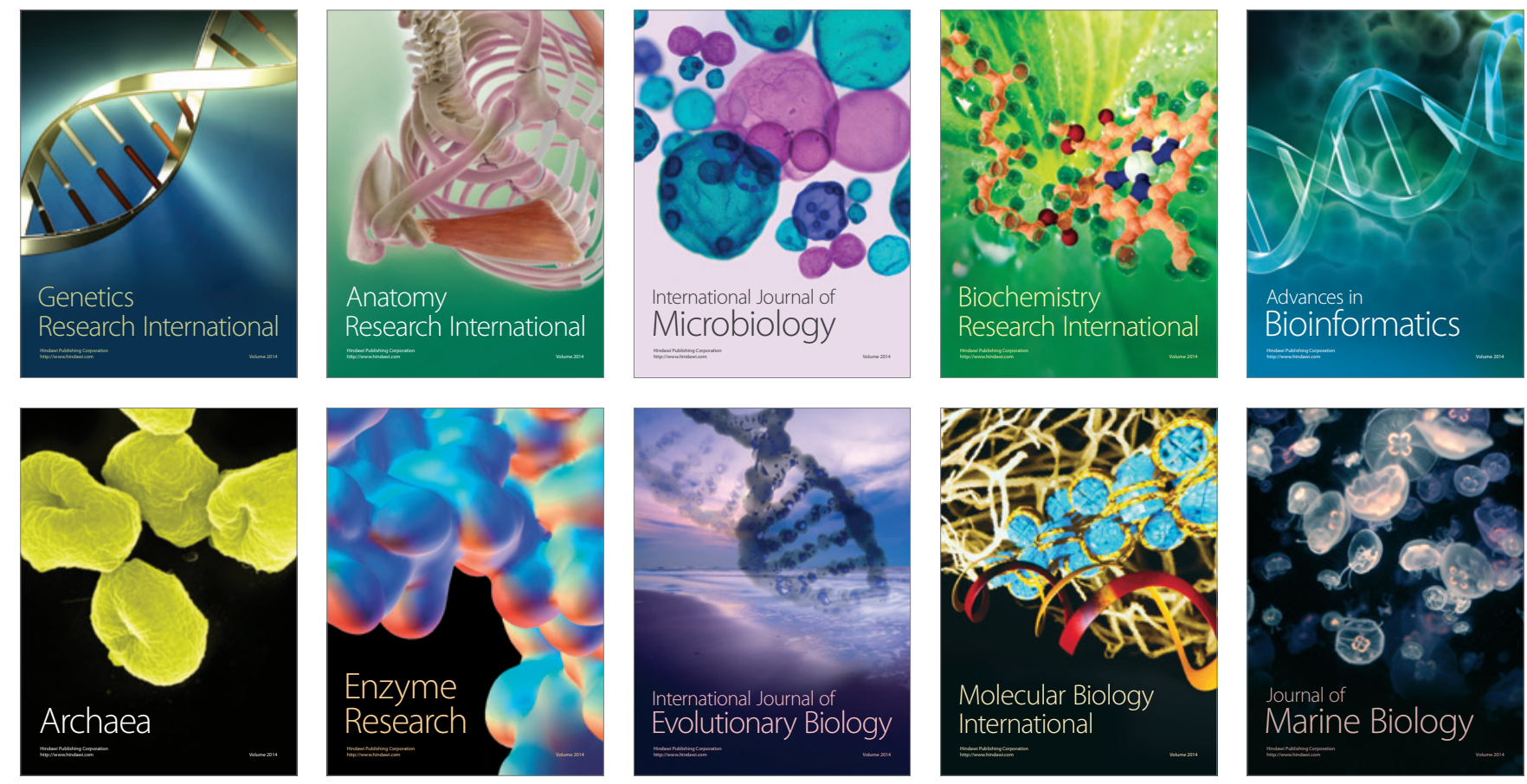